\title{
REFLEXÕES A PARTIR DA PSICOLOGIA SÓCIO-HISTÓRICA SOBRE A CATEGORIA "CONSCIÊNCIA"
}

\author{
WANDA MARIA JUNQUEIRA AGUIAR \\ Doutora em Psicologia Social e Docente na Faculdade de Psicologia da PUC/SP
}

\begin{abstract}
RESUMO
Este artigo pretende ser uma contribuição para o estudo da categoria consciência numa perspectiva sóciohistórica, por conseguinte, elegemos Vygotski como o autor central para o desenvolvimento de nossas reflexôes. Para a sua realização, além de Vygotski e de alguns leitores de sua obra, consideramos as contribuições de Fernando G. Rey e de Agnes Heller. Pela articulação das contribuições teóricas apontadas, desenvolvemos algumas reflexões sobre a categoria consciência, ressaltando seu processo de constituição, suas mediações e sua importância para a compreensão das formas de pensar, sentir e agir do ser humano.

WYGOTSKI, LEVS. - REY, FERNANDOG. - HELLER, AGNES - PENSAMENTO-RELAÇÕES SOCIAIS

\section{ABSTRACT}

THECATEGORY “CONSCIOUSNESS": SOMEREFLECTIONSBASEDONSOCIOHISTOR/CPSYCHOLOGY. The presente article intends to be a contribution to the study of consciousness in a sociohistorical perspective, therefore we elected Vygotsky as our main author for the development of our refletions. To make this article possible, besides the contribution of the above mentioned author, we have used works of other authors who were also studies of Vygotsky books, and also two other authors, Agnes Heller and Fernando G. Rey. Through the articulation of the theoric contributions, we have developed some refletions about the consciousness category, stressing its constitution process, its mediations and importance to the understanding of human being ways of think, feel and act.
\end{abstract}


O objetivo deste artigo é apresentar algumas reflexões sobre a categoria consciência, ressaltando seu processo de constituição, suas mediações e sua importância para a compreensão das formas de pensar, sentir e agir do ser humano. Para tanto, far-se-á uso basicamente, ainda que não de maneira exclusiva, da proposta de Vygotski, um dos autores que, na perspectiva sócio-histórica, elaborou uma reflexão complexa e intrigante sobre tal questão. De fato, já em 1925, ao se referir à necessidade de avançarmos nos estudos sobre a consciência, Vygotski afirmava:

O estado em que se encontra a nossa ciência mantém-na ainda muito longe da fórmula final de um teorema geométrico que coroe com o último argumento, como queríamos comprovar. (1991, p. 29, tradução nossa)

autor tinha razão na época e ainda hoje a tem: apesar dos avanços alcançados nessa área, há ainda muito o que pesquisar sobre a questão da consciência. Ao debruçarse sobre a questão, Vygotski aponta o fato de que a exclusão da consciência do campo da psicologia científica sugere a adoção de dois caminhos muito diversos. De um lado, a postulação de uma psicologia sem "psique", quando se admite a possibilidade de o comportamento do homem ser explicado sem que se recorra a fenômenos subjetivos. De outro, a aceitação de uma psicologia que pretende estudar a "psique" pura, desvinculada do comportamento. Em ambos os casos, mergulha-se em uma posição dualista, na qual se institui a dicotomia entre objetivo/subjetivo e interno/externo.

No entanto, antes de avançar na análise da categoria da consciência, e até como condição para que se possa construí-la, parece ser necessário apontar a concepção de homem que embasa a produção vygotskiana e, de uma maneira mais geral, a psicologia sócio-histórica. Parece assim conveniente que se retome as reflexões de Schaff ( 1987 ) que, ao discutir a concepção marxista de indivíduo, afirma:

O ponto de partida lógico, nas considerações de Marx, é a convicção de que o homem existe como espécie e como indivíduo, que é um exemplar desta espécie, um resultado, um produto do desenvolvimento histórico, e, portanto, um produto social. (1987, p. 69)

homem é, assim, visto como um ser inerentemente social e, como tal, sempre ligado às condições sociais. Homem que, além de produto da evolução biológica das espécies, é também produto histórico, mutável, pertencente a uma determinada sociedade, em uma determinada etapa de sua evolução. Não se está simplesmente afirmando, no caso, que o homem se encontra ligado ao mundo e à sociedade ou que é influenciado por ela, mas sim que se constitui sob determinadas condições sociais, resultado da atividade de gerações anteriores.

Trata-se, neste caso, de adotar uma visão de indivíduo concreto, mediado pelo social, determinado histórica e socialmente, que não pode, jamais, ser compreendido in- 
dependentemente de suas relações e vínculos. Fala-se de um homem ativo que, como afirma Marx, não tem sua vida determinada pela própria consciência. Ao contrário, sua consciência é que é determinada por sua vida. Essa afirmação, para ser compreendida, exige, segundo Adorno (1978), a negação da teoria das mônadas, segundo a qual tudo o que acontece ao ser humano não passa de mera conseqüência de suas idéias ou noções.

Por outro lado, é preciso também que se evite a visão de homem que considera o ser humano como reflexo imediato do meio social, como um ser passivo, desprovido da possibilidade de criar, inovar. Trata-se, enfim, de encarar o homem como mediação, justamente pelo fato de se considerá-lo um ser histórico, mais do que cultural ou determinado pelas condições sociais presentes em seu tempo e espaço. Para que essas idéias, próprias da perspectiva sócio-histórica, fiquem mais claras, convém retomar uma questão fundamental: a de natureza humana versus condição humana.

Quando se parte do pressuposto de que o homem não é produto da natureza, não tem uma "natureza humana" inata e imutável, de caráter universal, faz-se necessário abandonar a idéia de que existe uma natureza humana, como ponto de partida. De fato, assumir esse último ponto de vista implica ser desnecessário situar o homem historicamente, pois seu desenvolvimento passa a ser visto como pura atualização dessa natureza, isto é, de algo já nele contido desde o nascimento e que desabrocha no decorrer de sua vida. Bock e Neves (1995) ilustram como a visão da natureza humana gera um processo de ocultamento das condições sociais constitutivas do sujeito:

A psicologia, ao estudar dessa forma o homem, faz um trabalho retórico de ocultamento das condições sociais que geram a desigualdade e geram os indivíduos atomizados, passando a fazer parte do aparato ideológico, que nos impede de enxergar e compreender a realidade social e, com ela, a realidade psíquica. (1995, p. I5)

Dessa forma, parece ser mais adequado a postulação de uma condição humana, na medida em que ela se refere a um homem que constrói sua existência a partir de uma ação sobre a realidade, com o objetivo de satisfazer suas necessidades. É, pois, por meio da ação significada no mundo que o homem vai não só transformar a realidade objetiva em realidade humana como também criar suas próprias condições de existência, transformando-se a si próprio. Homem e sociedade vivem, portanto, uma relação de mediação, em que cada pólo expressa e contém o outro, sem que nenhum deles se dilua no outro ou perca sua singularidade.

Dessa forma, a tarefa da Psicologia reside justamente na tentativa de compreender esse indivíduo em sua singularidade, singularidade essa que contém tanto a internalização como a expressão de sua condição histórica e social, sua ideologia e relações vividas. $\bigcirc$ resgate da singularidade do sujeito consiste, em última instância, na apreensão do processo particular pelo qual se dá a construção de sua consciência. Esse aspecto é bastante claro para Vygotski ( 1993): cabe à Psicologia, segundo o autor, possibilitar a descrição e a expli- 
cação das funções psicológicas superiores, ou seja, a apreensão da gênese social da consciência pelas suas mediações, como pensamento, linguagem e vontade.

Central e orientador da psicologia sócio-histórica é o postulado de Vygotski (1993) de que cada função psicológica no desenvolvimento cultural da criança aparece duas vezes, ou em dois planos: primeiro elas surgem no plano social e, depois, no plano psicológico. Essa formulação, de grande complexidade, traz implicações importantes para o desenvolvimento da Psicologia. A primeira delas reside no fato de representar forte crítica às teorias que afirmam serem as funções superiores resultado unicamente da maturação, partilhando, conseqüentemente, da idéia de desenvolvimento humano como um processo natural.

Segundo Wertsch (1988), Vygotski entendia que enquanto o desenvolvimento "natural" produzia tão somente funções primárias, o desenvolvimento "social" (cultural) as transformava em funções superiores. Melhor dito, transformava os processos elementares em processos superiores. As funções psicológicas superiores são, portanto, produto do meio sociocultural em que vivem imersos os homens. Vygotski (1993) afirma que a natureza psicológica dos homens representa o agregado de relações sociais internalizadas que se tornaram, para o indivíduo, funções e formas de sua estrutura. Assim, grande é a ênfase dada pelo autor à origem social da linguagem e do pensamento. De igual forma, outro ponto salientado por Vygotski é que as funções psicológicas superiores são produtos da atividade cerebral. Segundo ele, a psicologia dialética parte da unidade dos processos psíquicos e fisiológicos:

A psique não deve ser considerada como uma série de processos especiais que ocorrem em algum lugar acima e à parte dos processos cerebrais, senão como expressão subjetiva deles mesmos (processos), como uma característica especial das funções superiores do cérebro. ( 1991, p. 100)

Pode-se afirmar, portanto, que para a psicologia sócio-histórica, o homem é um ser ativo, social e histórico. Essa é a sua condição humana, a qual the permite constituir suas formas de pensar, sentir e agir, ou seja, constituir sua consciência. Mas como se dá este processo? O que exatamente se entende por consciência? Em 1924, Vygotski fez uma conferência intitulada "A consciência como problema da Psicologia do Comportamento". Nesse momento, o autor começava a desenvolver o princípio da gênese social da consciência individual e já apontava a palavra como origem da conduta social e da consciência. Com o desenvolvimento do pensamento de Vygotski, bem como com o de Leontiev e Luria, observa-se um avanço no conceito de consciência. Vygotski critica os reducionistas, sejam eles os objetivistas, sejam eles os subjetivistas. Para ele, o sujeito não se constitui com base em fenômenos internos e nem se reduz a simples reflexo passivo do meio. Como afirma Leontiev: "o reflexo da realidade objetiva pela consciência não se produz passivamente, mas de maneira ativa, criativa, sobre a base e no decorrer da transformação prática da realidade" (1978, p.121, tradução nossa). 
Segundo o mesmo autor, a realidade objetiva não depende de um homem em particular: ela preexiste e, nessa condição, passará a fazer parte da subjetividade de cada homem em particular. Nesse momento, ao mesmo tempo que é realidade objetiva, independente do sujeito em particular, ela "se nega enquanto tal" (como realidade objetiva), justamente porque passa a ser realidade subjetiva. Na passagem de "fora" para "dentro", a realidade objetiva, como coloca o autor, transforma-se: "representa o objetivo no subjetivo, uma forma particular de existir do mundo exterior no interior" (1978, p. 98). Nega-se, assim, a dicotomia objetividade-subjetividade, que passa a ser vista em uma relação de mediação, na qual um existe por intermédio do outro, sem que um se dilua no outro, perdendo sua identidade.

Será pela atividade externa, portanto, que se criam as possibilidades de reconstrução da atividade interna. Nesse ponto, cabe frisar que a atividade de cada indivíduo é determinada pela forma como a sociedade se organiza para o trabalho, entendido nesse caso como a transformação da natureza para a produção da existência humana, algo que só é possível na vida social. Nesse processo, o homem estabelece relações com a natureza e com os outros homens, determinando-se mutuamente. É nesse sentido que se afirma ser o homem ativo e social:

homem, ao nascer, é candidato à humanidade e a adquire no processo de apropriação do mundo. Nesse processo, converte o mundo externo em um mundo interno e desenvolve, de forma singular, sua individualidade. (Bock, Gonçalves, 1996, p. 3)

Se o plano individual não constitui uma mera transposição do social e se o movimento de apropriação envolve a atividade do sujeito, isso significa que o sujeito modifica o social, de forma que o social modificado representa a possibilidade do novo, da criação. A linguagem, segundo Vygotski (1993), também produzida social e historicamente, é o instrumento fundamental nesse processo de constituição do sujeito. Os signos, entendidos como instrumentos convencionais de natureza social, são os meios de contato com o mundo exterior e, também, do homem consigo mesmo e com a própria consciência.

As palavras desempenham um papel central não só no desenvolvimento do pensamento, mas também na evolução histórica da consciência como um todo. Uma palavra é um microcosmo da consciência humana. (Vygotski, 1993, p. 132)

Os signos representam, assim, a forma privilegiada de apreensão da consciência. Desse modo, Vygotski chega a uma de suas conclusões mais importantes, qual seja: "a análise semiótica é o único método adequado para estudar a estrutura do sistema e do conteúdo da consciência" (1991, p. |29). Entre os estudiosos do autor na atualidade, esse é um ponto controvertido, na medida em que entra em conflito com as idéias de Leontiev quanto à constituição da consciência. De fato, Leontiev vai propor e desenvolver a questão da atividade como sendo a unidade de análise mais adequada para o estudo da consciência 
humana. Entretanto, muitos de seus trabalhos restringem-se a registros e descrições de diferentes momentos da atividade, não se detendo nos processos psicológicos constitutivos da consciência.

Esse é o motivo pelo qual muitos autores, entre eles Rey (1996), entendem que a visão de Leontiev acerca da atividade assume um caráter externo, objetal, passivo e reprodutivista. Para esses autores, a atividade, tal como apreendem a proposta de Leontiev, parece estar mais orientada para o objeto do que para o sujeito ou para a comunicação, sendo incorporada ao plano interno mantendo essa mesma estrutura e sem a participação do sujeito. Como afirma Rey, Leontiev parece ter "confundido a atividade com os processos essenciais que ocorrem no plano subjetivo, interno, capazes de explicar o desenvolvimento humano". Em resumo, para Rey, "perde-se o sujeito".

Também, de acordo com Kozulin (1994), Leontiev insiste no papel dominante da ação prática, ou seja, na ação instrumental, não considerando a mediação semiótica. Leontiev acaba, assim, explicando a atividade humana pela própria atividade. Por outro lado, Vygotski destaca e prioriza a esfera simbólica e comunicativa da atividade humana, sem esquecer, é claro, que a linguagem e outros mediadores semióticos de forma alguma podem ser vistos como independentes da realidade material e da prática humana.

Para Vygotski, no entanto, a atividade humana não é internalizada em si, e sim como atividade significada, tal como um processo social, mediado semioticamente. A consciência, dessa forma, é semioticamente estruturada, resultado dos próprios signos, ou seja, de instrumentos construídos pela cultura e pelos outros que, quando internalizados, se tornam instrumentos internos e subjetivos da relação do indivíduo consigo mesmo. Signo é, pois, entendido neste caso como tudo aquilo que possui um significado e que remete a algo situado fora de si mesmo: é o elemento que integra as funções psíquicas superiores.

Da mesma forma, Bakhtin (1991) vai destacar a importância dos signos. Para ele, a palavra, além de constituir a chave para a compreensão da consciência e da subjetividade, é também espaço privilegiado de criação ideológica. Diferentemente do sinal, inerte, o signo é vivo, móvel, plurivalente, jamais monovalente ou neutro. A palavra, portanto, é vista como a arena onde se confrontam valores sociais contraditórios, conflitos, relações de dominação etc.

Para Bakhtin!: "todo signo é ideológico; a ideologia é um reflexo das estruturas sociais; assim, toda modificação da ideologia encadeia uma modificação na língua" ( 99 | , p. 15). A palavra (signo ideológico) vai, dessa maneira, sempre estar apontando as menores variações das relações sociais, não só as referentes aos sistemas ideológicos constituídos, mas também, no que diz respeito à "ideologia do cotidiano", aquela que se exprime na vida corrente, em que se formam e se renovam as ideologias já constituídas. Vê-se, dessa for-

I. Para Bakhtin, ideologia é o espaço de contradição e não apenas de ocultamento, como em Marx. Ideologia, ainda, é uma forma de representação do real. Finalmente, tudo o que é ideológico é, para Bakhtin, signo. 
ma, que os sistemas semióticos não só exprimem a ideologia como são determinados por ela. Ou seja, os signos não só refletem a realidade como constituem um de seus fragmentos materiais.

Já para Vygotski, é fundamental que não se compreenda o signo simplesmente como uma ferramenta que transforma o mundo externo. Diferentemente dos instrumentos, orientados para regular os objetos externos que, na realidade, constituem condutores da influência humana sobre o objeto da atividade, os signos são orientados para regular as ações sobre o psiquismo das pessoas. No caso, como bem coloca Wertsch (1988), o signo como instrumento psicológico não muda em nada o objeto de uma operação psicológica, mas influencia psicologicamente tanto a conduta própria como a do outro. O signo é visto, desta forma, como um meio de atividade interna. De igual modo, Pino ( I99| , p.36) aponta que "a natureza reversível dos signos torna-os particularmente aptos para a regulação da atividade do próprio sujeito, fazendo deles os mediadores na formação da consciência, experiência das experiências". Entretanto, como destaca Riviére (1988, p.43), é fundamental a compreensão de que os signos, antes de serem meios de atividade interna, são mediações externas, surgem da relação com o outro: "como mediações externas (antes de se interiorizarem), os signos são desenvolvimentos ontogenéticos a partir da própria conduta instrumental".

Para que se esclareça o processo dialético de construção dos signos, faz-se importante a reflexão sobre o processo de internalização, entendido como aquele em que certos aspectos da estrutura da atividade, que se realizaram no plano externo, passam a acontecer no plano interno. Internalização não é, pois, a transferência do externo para o plano da consciência, mas os processos mediante os quais esse último plano é formado. A consciência, como um processo, abriga o aspecto psicológico, ou seja, a realidade social transformada em psicológica. Esse processo, sempre em elaboração, redunda em formas de pensar, sentir e agir, que estão, também, sempre em construção. Dessa maneira, o homem, ao internalizar alguns aspectos da estrutura da atividade, internaliza de fato não apenas uma atividade, mas uma atividade com significado, como um processo social que, como tal, é mediado semioticamente, ao ser internalizado.

Uma outra questão fundamental para Vygotski diz respeito ao fato de que as funções psicológicas, como toda produção cultural e social, são produtos da atividade humana. $\bigcirc$ homem transforma a natureza com sua atividade por meio dos instrumentos e, assim, transforma-se a si próprio. Dessa maneira, se o ser humano forma-se por meio de uma relação dialética com a realidade social, não cabe a idéia de que a constituição do sujeito resulte de uma mera transposição do plano social para o individual. A constituição do sujeito é vista, pois, como resultado de um processo de conversão do social no individual, sem que indivíduo e sociedade mantenham entre si uma relação isomórfica.

Pino (1995) oferece algumas pistas acerca de como melhor compreender o termo conversão, de que fala Vygotski. Indica, como uma das mais interessantes, aquela ligada ao 
uso do termo para designar mudanças pelas quais o indivíduo pode passar. Essa pista, segundo Pino (1995, p. 3),

...aponta no sentido de que a conversão é um processo semiótico: descobrir/assumir uma significação nova das coisas. [...] A conversão de que fala Vygotski consistiria em transformar materialidades concretas em produções simbólicas, como é próprio de toda atividade humana.

Assim, progressivamente, pela mediação das relações sociais, o homem vai se constituindo em uma "unidade de produção", na qual, em um processo contínuo, matéria será convertida em produções semióticas e processos de dimensão social serão convertidos em processos de dimensão individual. A noção de conversão pressupõe, portanto, a noção de superação e de mediação, pois o que ocorre não é a internalização de algo de fora para dentro, mas a conversão de algum elemento da realidade social, em algo que mesmo permanecendo quase social se transforma num elemento constitutivo do sujeito.

Retoma-se, assim, a idéia de que, para compreender a gênese da consciência, é necessário analisar os processos de internalização da linguagem. Se a gênese da consciência reside na compreensão da atividade significativa - atividade de transformação mediada e instrumental do meio -, chega-se ao significado da palavra como unidade de análise da consciência, visto conter as propriedades do todo, elementos constitutivos e inseparáveis: o pensamento e a linguagem. Para Vygotski:

O significado de uma palavra representa um amálgama tão estreito do pensamento e da linguagem, que fica difícil dizer que se trata de um fenômeno da fala ou um fenômeno do pensamento. (1993, p. 104)

Assim, "o significado é fenômeno do pensamento apenas quando o pensamento ganha corpo por meio da fala, e só é fenômeno da fala na medida em que a palavra está ligada ao pensamento, sendo iluminada por ele" (Freitas, 1994, p.94). A linguagem é, portanto, instrumento fundamental no processo de mediação das relações sociais, por meio do qual o homem se individualiza, humaniza-se, apreende e materializa o mundo das significações que é construído no processo social e histórico.

Na tentativa de melhor explicitar a constituição da consciência pelas relações de mediação (em que o sujeito constitui-se pelo outro e pela linguagem), parece oportuno considerar a forma como Smolka, Góes e Pino (1995) discutem o conceito de intersubjetividade. Segundo tais autores, esse conceito vem recebendo interpretações que, de uma maneira geral, convergem para uma compreensão harmoniosa de intersubjetividade: um espaço de "entendimento mútuo", de "diálogo simétrico". Os autores acima discordam dessa interpretação, visto ela não contemplar conflitos, oposição de idéias, resistência à comunicação e outros aspectos não harmônicos da comunicação.

Em pesquisas, Smolka, Góes e Pino (1995, p.22) desenvolvem a concepção de que a constituição do sujeito pelo outro se dá no campo da intersubjetividade, entendida como 
"o lugar do encontro, do confronto e da negociação dos mundos de significação privados (ou seja, de cada interlocutor) à procura de um espaço comum de entendimento e produção de sentido, mundo público de significação". Logo, é no campo da intersubjetividade que se dá a consciência da subjetividade e a penetração no universo da significação. Deve ficar claro, como afirma Góes, que

...se o plano intersubjetivo não é o plano do outro (é uma relação onde um contém o outro, um é determinado pelo outro), se o reflexo do plano intersubjetivo sobre o intra-subjetivo não é de caráter especular e se as ações internalizadas não são a reprodução de ações externas mediadas socialmente, então o conhecimento do sujeito não é dado de fora para dentro, suas ações não são linearmente determinadas pelo meio nem seu conhecimento é cópia do objeto. (1991 , p. 20)

Fundamental para compreendermos as funções psicológicas e a própria consciência é a investigação sobre as formas de significação, entendidas neste trabalho e de acordo com Pino (1995, p.3), "como tudo aquilo que a partir do signo pode ser socialmente pensado, dito e feito". A compreensão da gênese da consciência dar-se-á, portanto, pelo entendimento da atividade significativa, atividade de transformação mediada e instrumental do meio, em última instância, pelo significado da palavra. Dessa forma, não há como não concordar com Pino ( 1995$)$, quando afirma que uma das maiores contribuições de Vygotski é ter colocado no centro da análise psicológica a atividade mediada por instrumentos, focalizando a "mediação semiótica".

De fato, as formas de significação, que traduzem as formas de sociabilidade humana, permitem compreender não só a constituição das funções psicológicas superiores como a própria consciência. A significação, dessa maneira, não pode ser entendida como algo pronto. Ao contrário, deve ser vista como um processo no qual constantemente os signos, ou significados instituídos, são reelaborados em razão de condições históricas próprias. Vale dizer que os processos de significação são, de um lado, constituintes da consciência e, de outro, sua função.

A consciência, portanto, surgirá não só mediante a encarnação dos signos, mas também por intermédio do processo de significação, que traduz as condições de funcionamento da sociedade, suas estruturas de relação e suas práticas sociais. Mas a consciência pertence, também, a um sistema com leis específicas, que é o sistema psíquico. Todo fenômeno ideológico, ao longo do processo de sua criação, passa pelo psiquismo, ou seja,

...todo signo ideológico exterior, qualquer que seja sua natureza, banha-se nos signos interiores, na consciência. Ele nasce deste oceano de signos interiores e aí continua a viver, pois a vida do signo exterior é constituída por um processo sempre renovado de compreensão, de emoção, de assimilação, isto é, por uma integração reiterada no contexto interior. (Bakhtin, 1991, p. 57)

No esforço de compreender a consciência pelos processos de significação, não se pode esquecer que essa atividade significativa não é simplesmente cognitiva e intelectual: 
ela contém, ainda, uma dimensão emocional. A consciência constitui a forma como o indivíduo apreende o mundo físico e social, "em um trabalho de interpretação da vida, de nós mesmos, da relação com o mundo, através do pensar, do sentir, do sonhar" (Sawaia, 1987, p. 296). A emoção deve, portanto, ser vista como dimensão fundamental da consciência, um de seus elementos constitutivos, ao lado da linguagem e do pensamento.

Apesar de Vygotski não ter desenvolvido estudos sistemáticos sobre as emoções, elas aparecem como sua primeira inquietação, em "Psicologia da Arte". Em momentos posteriores, ele também as aborda, ao discutir os processos motivacionais e o próprio pensamento. Segundo Vygotski, pensamento e emoção não podem ser compreendidos de forma dicotomizada, uma vez que o processo cognitivo não existe descolado da emoção: independentemente de o pensamento ser lógico ou emocional, ele sempre será um fenômeno que tem como base a emoção.

Discutindo inexistência de dicotomia entre pensamento e emoção, Vygotski afirma que:

.... pensamento propriamente dito é gerado pela motivação, isto é, por nossos desejos e necessidades, nossos interesses e emoções. Por trás de cada pensamento há uma tendência afetivovolitiva, que traz em si a resposta ao último "por que" de nossa análise do pensamento. Uma compreensão plena e verdadeira do pensamento de outrem só é possível quando entendemos sua base afetivo-volitiva. (Vygotski, apud Lane, Camargo, 1994, p. I 18)

Dessa forma, o atuar, pensar, sentir, perceber constituem um processo único, cujas partes só se diferenciam funcionalmente para, em um outro processo paralelo, novamente virem a se integrar.

Lane (1994, p. 57) aponta que, para Vygotski, as emoções têm uma natureza social e um caráter comunicativo, afirmando que elas "se constituem em uma linguagem, cujas mensagens podem tanto desencadear o desenvolvimento da consciência como fragmentála". Assim, o pensamento deve ser concebido como emocional e a linguagem como algo sempre emocionado, ou seja, ambos terão como elemento constitutivo a dimensão afetiva, expressando uma avaliação do sujeito.

Cabe aqui destacar a contribuição de Heller (1985) para a compreensão dessas questões. Para a autora, um aspecto essencial a ser considerado nessa discussão é a unidade entre sentimento, pensamento e moralidade. Sentimentos não podem jamais ser tratados e apreendidos fora do conhecimento e/ou da ação moral e vice-versa. De fato, segundo Heller, sentir - seja positiva ou negativamente - significa estar implicado em algo e, dessa forma, a implicação vai estar sempre presente no atuar e no pensar. A implicação, nesse sentido, representa "um fator constitutivo e inerente do atuar e pensar; a implicação está incluída em tudo isso, por via da ação ou da reação" (1985, p. 19).

Ao discutir o conceito de implicação, Heller afirma ser inconcebível haver implicação zero, ou seja, a presença de um acontecimento sem significado. Não obstante, pode 
ocorrer, sim, situações de baixa implicação, muitas vezes relacionadas àquelas situações rotineiras, repetitivas. No entanto, diante do surgimento de obstáculos, novas vivências são suscitadas, tanto cognitiva como afetivamente, surgindo novos significados, gerando inquietação, movimento, novas possibilidades e, conseqüentemente, uma maior implicação. Desse modo, a implicação é vista como parte estrutural, inerente ao pensamento e à ação. De igual forma, a compreensão do sentir, como "estar implicado em", requer a clareza de que "subjetivação e objetivação são no desenvolvimento do homem e no do indivíduo duas direções inseparáveis, interdependentes e tangenciais" (1985, p. 30).

O ser humano, ao nascer, traz consigo um código genético que tem inscrito somente as condições para a existência da espécie, o que Heller denomina de "essência muda da espécie". No entanto, o caráter próprio da espécie humana é externo aos indivíduos no momento de seu nascimento. Assim, segundo a autora,

.... homem nasce com uma máquina (cérebro) programada para operações ideativas (simbólicas) e para projeções, com capacidade de armazenar memória e desenvolver operações simultâneas. Sem dúvida, tais tarefas não são subministradas pelo cérebro no momento do nascimento. São subministradas pelo mundo, pelo ser no mundo, pela subsistência e orientação nele, pelo sistema de símbolos, como a linguagem, as formas de manipulação, as objetivações em geral; dito de outro modo, pelo caráter próprio da espécie". (1985, p. 32)

Em sua existência, portanto, o homem começa a se apropriar das tarefas do mundo e a integrá-las, desenvolvendo, assim, a relação sujeito/objeto, que o caracteriza como ser humano. Uma relação de apropriação, de objetivação e de expressão que, sem dúvida, corresponde ao agir, pensar e sentir, características das manifestações da vida humana. Dessa maneira, implicação constitui uma função reguladora do organismo social do sujeito, de modo que estar implicado significa "regular a apropriação do mundo", "avaliar, para si mesmo, a essência própria da espécie". Em última instância, o sentimento informa sobre a importância do objeto para o sujeito e não sobre a natureza do objeto; fornece informação sobre o que realmente se é; avalia o significado dos objetos para o sujeito.

Todavia, não se pode esquecer, como bem aponta Heller, que implicação não constitui somente uma função reguladora do organismo social do ponto de vista da relação sujeito/objeto. Sem dúvida, o homem também faz, de si mesmo, objeto de sua consciência, ou seja, sem a consciência de si, não pode haver ser humano. No entanto, o processo de estar implicado em algo pode se dar de diferentes formas: "o centro da minha consciência pode estar ocupado pela própria implicação, ou pelo objeto em que estou implicado. Portanto, o sentimento pode ser figura ou fundo" (Heller, 1985, p.23).

Para a autora, sentimento e emoção são diferentemente conceituados. Em um processo de estar implicado em algo, se a tônica estiver na implicação, a emoção estará no centro da consciência, ou seja, pode-se dizer que dos elementos componentes da organização da consciência, a emoção ocupa lugar central. Por outro lado, se a tônica 
estiver em algo em que se está implicado (por exemplo, a própria tarefa), o sentimento é "fundo". Sintetizando, Heller coloca que seria mais adequado afirmar que a emoção tende a ser "mais figura", e o sentimento, "mais fundo". A implicação aparece como "figura" (como emoção) em casos em que a ação, o pensamento ou a relação com alguém (ou com algo) se encontra impedida. Por outro lado, quando se está concentrado na resolução de um problema, a implicação tende a permanecer mais como "fundo" (como sentimento). A autora deixa claro, portanto, que a implicação é parte inerente, estrutural, e não mero acompanhamento da apreensão intelectual. Vê-se, então, que para compreender a construção social da consciência, o pensar, agir e sentir só podem ser vistos de maneira integrada.

Entretanto, como já referido anteriormente, muitas lacunas se mantêm na busca de compreensão do homem como um ser único, social e histórico. Como um exemplo das várias questões que merecem maior aprofundamento, destaca-se o fato de que apesar das emoções serem sempre constituídas a partir das experiências, elas são, por um lado, significadas (passando a ter um sentido para o sujeito e podendo ser expressas pela linguagem) e, por outro, podem não o ser (permanecendo inconscientes). Tal reflexão implica uma discussão bastante complexa: a questão do inconsciente, definido de forma semelhante por Vygotski, Heller e Rey.

Para Vygotski ( 199 |), o inconsciente constitui os aspectos não significados, aqueles que, muitas vezes, são cultural e socialmente negados: "a vida psíquica supõe uma série de fenômenos excessivamente fragmentários, que continuam a existir mesmo sem termos consciência deles" (p. 105). Assim, "pode parecer que fazemos algo por uma causa determinada mas, na realidade, a causa é outra" (p. 104).

Já para Rey (1996), consciente e inconsciente constituem uma unidade, ainda que, sem dúvida, vivam uma tensão constante. Para esse autor, o inconsciente refere-se a tudo que não se encontra simbolizado no momento atual. De fato, os indivíduos vivem experiências que não necessariamente passam pelo canal da simbolização: são vividas, mas não significadas. Os indivíduos, diante de algumas experiências, não conseguem apreender os múltiplos estados emocionais nelas envolvidos. Pode-se dizer que o sentido que daí emerge não é totalmente significado: alguns aspectos permanecem inconscientes. Dessa forma, mesmo aquelas emoções que aparentemente são significadas pelo sujeito, que podem ser nomeadas, não necessariamente são apreendidas em sua complexidade: o que emerge, o que é apreendido pelo próprio indivíduo, pode ser algo fragmentado, descolado de seu processo de constituição. É freqüente a expressão de significações fortemente emocionais mas extremamente confusas e contraditórias, descoladas de sua história. Pode-se dizer que essas expressões contêm elementos não significados.

Heller (1985), por sua vez, considera inconsciente as unidades de memória em que o acontecimento é armazenado sem conceitualização. Isso decorre de um duplo movimento, ou seja, por um lado, não se tem claro seu significado, ou seja, não somos ainda 
capazes de inseri-lo em nosso mundo; por outro, somos capazes de reconhecer a importância desse acontecimento, razão pela qual o armazenamos.

Consciência e inconsciente vivem, assim, uma relação de mediação, na qual um não se dilui no outro, cada qual mantendo sua identidade, ainda que um não exista sem o outro. Pode-se afirmar, portanto, que o inconsciente é parte constitutiva da consciência e vice-versa. Nessa medida, convém ressaltar que também o inconsciente é histórico e social, a despeito de, ao mesmo tempo, ser individual, singular. Tentando esboçar uma análise da relação entre consciente e inconsciente, da tensão constante existente entre eles, acredita-se que será pelo movimento de ressignificação, da dinâmica que o inconsciente impõe à consciência, que os aspectos não significados podem se articular, integrando-se ao processo de ressignificação e se tornando, dessa forma, conscientes.

Dessa maneira, empenho deve ser feito visando à compreensão das formas de significação expressas pelo sujeito, tendo clareza de que não se pode ficar na aparência: há que se alcançar explicações para os sentidos atribuídos, de modo que se revelem e se explicitem as formas de pensar, sentir e agir. Será pelas significações (mesmo que carregadas de emoções mal apreendidas pelo sujeito), pela busca de suas determinações, que se poderá investigar a constituição histórica e social, única e irrepetível do sujeito. Desse modo, não há como discordar de Rey, quando ele afirma que:

.... análise psicológica não pode ficar no plano da atividade e de suas operações, mas dirigir-se às operações e mecanismos internos, subjetivos, os quais estão na base das diferentes formas de atividade que, de alguma maneira, mudam e se desenvolvem através dela. (1996, p. 5)

Nas reflexões desse autor, é fundamental a concepção de que o interno participa da construção do signo. $\bigcirc$ homem, segundo Rey, quando internaliza o mundo à sua volta, transforma o social em subjetivo. A subjetividade também tem um papel produtor, pois coloca o novo no social; de outra forma, não haveria relação dialética. A história encontrase no plano da cultura (sociogenético), no plano externo, mas também está no individual (ontogenético), no plano interno, o qual propicia ao sujeito a produção do novo, que completa a relação dialética. Ainda que não se saiba exatamente como esse processo se dá, como afirma Rey, "o pensamento não pode ser barrado porque não sabemos como tal processo acontece".

Dentre as contribuições de Rey, destacam-se suas reflexões em torno do que denomina "configurações subjetivas". Essa categoria parece abrir novas possibilidades de se alcançar uma compreensão mais profunda de como o indivíduo internaliza o social, construindo sua forma de pensar e sentir o mundo. Na verdade, a análise das "configurações subjetivas" pode constituir uma via privilegiada para se chegar a uma visão mais complexa e totalizadora do sentido subjetivo atribuído pelo sujeito, permitindo um avanço na compreensão de suas operações e mecanismos internos e subjetivos e, assim, da constituição de sua consciência. 
Segundo Rey, as "configurações subjetivas" devem ser compreendidas como uma categoria que pretende explicar uma zona do real, possibilitando uma maior compreensão da constituição do interno e, mais precisamente, do novo. Segundo o autor, "as configurações são categorias complexas, pluridimensionais, que representam a unidade dinâmica na qual se definem os diferentes sentidos subjetivos dos eventos sociais vividos pelo homem" (1996, p. 99, tradução nossa). Neste sentido, o autor chama a atenção para o fato de que o externo só adquire sentido no momento em que entra em contato com o interno, uma vez que o externo, em razão de sua própria condição, não pode definir o interno. A história do próprio interno, do subjetivo, é que vai alocar significado ao externo.

Deste modo, no processo constante de internalização, o social aparece "configurado" em termos subjetivos, ou seja, a realidade aparece de outra maneira, constituída subjetivamente, na forma de configuração. Segundo Rey, "as configurações constituem-se no plano psicológico mas, simultaneamente, são expressões das diferentes atividades e relações sociais desenvolvidas pelo sujeito". Ainda segundo o autor:

... as configurações não se constituem em uma expressão de uma lógica do interno ou do externo, senão que expressão de uma lógica em que o externo e o interno se integram, dando lugar a um novo processo, no qual o interno permanentemente se externaliza e vice-versa. ( 1996, p. 100, tradução nossa)

Fica claro, portanto, que o social não pode ser definido como externo ao subjetivo: ele é, antes, um dos seus determinantes essenciais. Por outro lado, o social é, sim, externo, visto que, como forma de realidade, não se esgota naqueles aspectos que são significados pelo sujeito individual. De igual modo, o social é também interno, porque sua significação depende de um processo de constituição de sentido, no qual interno e externo perdem sua condição de antinomia e se integram em uma complexa relação de mediação. A partir dessas colocações, é possível considerar que a realidade aparece constituída subjetivamente, na forma de configuração, permitindo apreender os sentidos subjetivos que se organizam em torno de determinados fatos, objetos, eventos etc.

Um exemplo do próprio Rey (1996) pode auxiliar a compreender melhor esta intrincada questão. Escolheu-se a atividade de leitura, por ser considerada de natureza social e socializadora. Inicialmente, para entender o sentido subjetivo que a leitura tem para o sujeito, deve-se perguntar pelos motivos que o impulsionam a essa atividade, verificando-se que uma multiplicidade deles se organiza em seu redor, a vontade de ler talvez sendo o motivo mais importante. No entanto, para que se possa compreender qual a configuração psicológica que se constitui em torno dessa atividade (compreendida como um conjunto de relações), torna-se necessário que se busque o maior número possível de elementos (motivos) envolvidos. Assim, além da vontade de ler, outros motivos aparecem configurados: a necessidade de comunicação, a possibilidade de independência adquirida com a leitura, o desejo de aumentar a auto-estima, a segurança etc. 
Vê-se que, para o autor, diferentemente de Leontiev, o que motiva não é o fim (o objeto), mas o sentido que a leitura, no caso, tem para o sujeito. De fato, a leitura produz múltiplas emoções (muitas delas nem mesmo apreendidas) que geram "estados subjetivos", os quais, por sua vez, podem desenvolver ou levar, como já apontado, à necessidade de auto-estima, independência etc. Essas necessidades, construídas ao longo da história do indivíduo, vão se configurando em motivos específicos para a leitura. A inter-relação dinâmica desses diferentes elementos (motivos) leva-os a se constituírem como "estados portadores de um valor emocional estável”.

Serão justamente esses "estados emocionais estáveis" que definirão o sentido subjetivo atribuído pelo sujeito à leitura. Ou seja, da articulação desse conjunto de diferentes elementos (motivos carregados de emoções) surgem algumas emoções mais fortes, estáveis, irrepetíveis, que conferem, para um dado sujeito, sentido à atividade de leitura. Mas o sentido subjetivo terá, necessariamente, alguns aspectos significados e outros não, ou seja, vários aspectos constitutivos da configuração não são significados, vale dizer: não são conscientes.

O sujeito pode processar cognitivamente uma ou mais emoções envolvidas e que podem preponderar na configuração, chegando a um sentido, sem necessariamente, no entanto, apreender a multiplicidade de estados emocionais presentes. Certamente, o próprio processo de constituição das emoções envolvidas na configuração permanece oculto para o sujeito. Pode-se dizer que o caminho desejável seria o de se apropriar do maior número possível de elementos constitutivos das configurações, tornando-os conscientes. Deve ficar claro que as configurações são históricas e se modificam ao longo da vida: transformam-se em atividade, em história, em relacionamentos. Dessa maneira, falar de sentido subjetivo, expresso pelo sujeito num determinado momento, acerca de determinado objeto ou fato social, não expressa a totalidade das emoções vividas e historicamente constituídas. A categoria "configurações subjetivas" permite, pois, alcançar aos sentidos subjetivos, que se constituem, como afirma Rey (1996), para além de um fato cognitivo, um afeto constituído.

As configurações podem, ainda, conter elementos antagônicos, sentimentos conflitantes, fazendo com que as emoções que aparecem como predominantes e mais estáveis gerem um sentido subjetivo contraditório, que inclua prazer e desprazer, amor e ódio. As configurações devem, pois, ser vistas sempre em movimento, em constante interpenetração, em contínua transformação diante de novas atividades, de novas relações e de novas necessidades. Dependendo das relações estabelecidas, elementos dinâmicos alteram-se, transformando a configuração e, portanto, o sentido subjetivo que, dessa forma, só pode ser entendido como histórico e dinâmico.

A compreensão das emoções é fundamental para que se possa pensar em como as modificações se processam. De fato, na base, e mesmo constituindo as contradições, há sentimentos muitas vezes não significados, que movimentam e estimulam novas posições e 
alterações. A mudança, nessa ótica, é encarada como um processo subjetivo, mas de natureza social, no qual as relações vividas vão sendo integradas de maneira contraditória pelo sujeito: o diferente move o constituído, que se desintegra ao integrar o externo. A subjetividade é, assim, histórica: constrói-se ao longo da vida do sujeito e, por essa razão, não pode refletir o imediato, uma vez que a história da subjetividade deverá, também, incorporar e refletir a realidade objetiva. Ora, para que mudanças - determinadas historicamente, como processo subjetivo, que integra tanto aspectos significados (conscientes) como não significados (inconscientes) - ocorram, não basta o processo de assimilação e construção do novo, pela linguagem e pensamento, ainda que ambos sejam sempre mediados por sentimentos. Segundo Rey (1996), é necessário que as configurações se alterem, de modo que o novo mobilize não apenas as significações constituídas, como também os sentimentos não significados, construídos não intencionalmente. De outra forma, corre-se o risco de que, sem a desintegração do constituído, surjam sentimentos impeditivos da integração do novo.

Vê-se, então, que as formas de pensar e sentir o mundo expressam uma integração, muitas vezes contraditória, de experiências, de conhecimentos (aspectos significados), de uma história social e pessoal (mediada pela ideologia, pela classe social, pelas instituições etc.) e de emoções vividas, mas não necessariamente significadas. Finalizando, a consciência deve ser vista como um sistema integrado e multideterminado, em uma processualidade permanente, na qual é possível a reconstrução interna do mundo objetivo. As colocações feitas até o momento evidenciam a dialética da consciência: o quanto ela é tencionada por produtos históricos e pela subjetividade dos sujeitos, o quanto ela é social e ideológica, intersubjetiva e particular. Isso posto, mais uma vez parece ser preciso concordar com Vygotski quando ele afirma que "não temos de ignorar os fatos da consciência, mas materializá-los, transladá-los a um idioma objetivo que existe na realidade e desmascarar e enterrar para sempre as ficções, fantasmagorias etc.." (| 99|, p.44).

\section{REFERÊNCIAS BIBLIOGRÁFICAS}

ADORNO, T. W. Educação e emancipação. São Paulo: Paz e Terra, 1995.

ADORNO, T. W., HORKHEIMER, M. (org). Temas básicos de sociologia. São Paulo: Cultrix, 1978.

BAKHTIN, M. M. Marxismo e filosofia da linguagem. São Paulo: Hucitec, 199l.

BOCK, A. M. B., GONÇALVES M.G.M. et al. A Psicologia sócio-histórica, 1996, mimeo.

BOCK, A. M. B., NEVES, W. M. J. Por uma prática promotora de saúde em orientação vocacional. A Escolha profissional em questão. São Paulo: Casa do Psicólogo, 1995.

CHAUÍ, M. H. S. Ideologia e educação. In: Educação e Sociedade, Campinas: Cedes, n. 5, 1980. 
CODO, W. (org). Psicologia social: o homem em movimento. São Paulo: Brasiliense, 1984.

FREITAS, M. T. A. Psicologia e Educação: um intertexto Vygotski e Bakhtin. São Paulo: Ática, 1994.

GÓES, M. C. R. Os Modos de participação do outro no funcionamento do sujeito. Cadernos Cedes, Campinas: Cedes, n. 24. 1992.

A Natureza social do desenvolvimento psicológico. Cadernos Cedes, Campinas: Cedes, n. 24. 1991.

HELleR, A. O Cotidiano e a história. São Paulo: Paz e Terra, 1989.

A Teoria das necessidades. Barcelona: Península, 1986.

Teoria de los sentimientos. Barcelona: Fontamara, 1985.

JOBIM E SOUZA, S. Infância e linguagem: Bakhtin, Vygotski e Benjamin. Campinas: Papirus, 1985.

KOZULIN, A. La Psicología de Vygotski. Madri: Alianza, 1994.

LANE, S. T. M. Avanços da psicologia social na América Latina. In: LANE, S. T. M., SAWAIA, B. (orgs). Novas veredas da psicologia social. São Paulo: Brasiliense, 1994.

LANE, S. T. M. A Mediação emocional na construção do psiquismo humano. In: LANE, S. T. M., SAWAIA, B. (orgs). Novas veredas da psicologia social. São Paulo: Brasiliense, 1994.

LANE, S. T. M., CAMARGO, D. Contribuição de Vygotski para o estudo das emoções. In: LANE, S. T. M., SAWAIA, B. (orgs.). Novas veredas da psicologia social. São Paulo: Brasiliense, 1994.

LEONTIEV, A. Atividade, conciencia y personalidad. Buenos Aires: Ciencias del Hombre, 1978.

Desenvolvimento do psiquismo. Lisboa: Livros Horizonte, s.d.

LÖWY, M. Ideologias e ciência social: elementos para uma análise marxista. São Paulo: Cortez, 1988.

MÉSZÁROS, I. Marx. a teoria da alienação. Rio de Janeiro: Zahar, 1981.

MOLON, S. A Questão da subjetividade e da construção do sujeito nas reflexões de VYGOTSKI. São Paulo, 1996. Dissert. (mestr.) PUC/SP.

MONTERO, M. Estratégias discursivas ideológicas. In: LANE, S. T. M., SAWAIA, B. (orgs.). Novas veredas da psicología social. São Paulo: Brasiliense, 1994. 
PINO, A. O Conceito de mediação semiótica em Vygotski e seu papel na explicação do psiquismo humano. Caderno Cedes, Campinas: Cedes, n.24. 1991.

A Questão da significação: perspectiva sociocultural. Campinas: FEA/UNICAMP, 1995. (temas em Neurologia, v. 4)

REY, F. G. Comunicación, personalidad y desarrol/o. Habana: Pueblo y Educación, 1995.

. Epistemologia cualitativa y subjetividad. Universidad de la Habana, 1996. (mimeo)

RIVIÉRE, A. La Psicologia de Vygotski. Madri: Visor Distribuciones, 1988.

RODRIGUEZ, G. P. L. Metodologia de la investigación pedagógica y psicológica. Habana: Pueblo y Educación, 1989.

SAWAIA, B. B. A Consciência em construção no trabalho de construção da existência. São Paulo, 1987. Tese (dout.) Psicologia Social - PUC/SP.

Cidadania, diversidade e comunidade: uma reflexão psicossocial. In: SPINK, M. J. P. (org.). A Cidadania em construção. São Paulo: Cortez, 1994.

SCHAFF, A. O Marxismo e o indivíduo. Rio de Janeiro: Civilização Brasileira, 1987.

SIGUÁN, M. (coord.). Actualidad de Lev. S. Vygotski. Barcelona: Anthropos Ed. del Hombre, 1987.

SMOLKA, A., GÓES, M. C. R., PINO, A. A Constituição do sujeito: uma questão persistente. In: WERTSCH, J., DEL RIO, P., ALVAREZ, A. Sociocultural studies of mind. New York: Cambridge University, 1995.

VYGOTSKI, L. S. La Conciencia como problema de la psicologia del comportamiento. Problemas teóricos y metodológicos de la psicologia. Madri: Visor Distribuciones, I991 . El Desarrollo de los procesos psicológicos superiores. Barcelona: Crítica, 1979. Pensamento e linguagem. São Paulo: Martins Fontes, 1993.

El Problema de la conciencia. Problemas teóricos y metodológicos de la psicologia. Madri: Visor Distribuciones, 1991.

La Psique, la conciencia, el inconsciente. Problemas teóricos y metodológicos de la psicologia. Madri: Visor Distribuciones, |99I.

WERTSCH, J. Vygotski y la formación social de la mente. Barcelona: Paidós, 1988. 